E3S Web of Conferences 1, 36005 (2013)

DOI: $10.1051 / \mathrm{e} 3$ sconf/20130136005

(C) Owned by the authors, published by EDP Sciences, 2013

\title{
UNEP Demonstrations of Mercury Emission Reduction at Two Coal-fired Power Plants in Russia
}

\author{
W. Jozewicz ${ }^{1}, \underline{\text { L. Sloss }^{2}}{ }^{\text {and G. Futsaeter }}{ }^{3}$ \\ ${ }^{1}$ ARCADIS, North Carolina, USA; wojciech.jozewicz@arcadis-us.com; mail to:soilchen@ntu.edu.tw \\ ${ }^{2}$ International Energy Agency - Clean Coal Centre, London, UK; lesleysloss@gmail.com \\ ${ }^{3}$ UNEP Chemicals Branch, Geneva, SWITZERLAND; gunnar.futsaeter@unep.org
}

\begin{abstract}
The United Nations Environment Programme (UNEP) partnership area "Mercury releases from coal combustion" (The UNEP Coal Partnership) has initiated demonstrations of mercury air emission reduction at two coal-fired power plants in Russia. The first project has modified the wet particulate matter (PM) scrubber installed in Toliatti thermal plant to allow for addition of chemical reagents (oxidants) into the closedloop liquid spray system. The addition of oxidant resulted in significant improvement of mercury capture from $20 \%$ total mercury removal (without the additive) up to $60 \%$ removal (with the additive). It demonstrates the effectiveness of sorbent injection technologies in conjunction with an electrostatic precipitator (ESP). ESPs are installed at $60 \%$, while wet PM scrubbers are installed at $30 \%$ of total coal-fired capacity in Russia. Thus, the two UNEP Coal Partnership projects address the majority of PM emission control configurations occurring in Russia.
\end{abstract}

Key words: mercury, coal combustion, mercury emission control technologies, UNEP

\section{Introduction}

Mercury emissions from combustion of coal in power plants and industrial boilers constituted about 26\% (or about 500 metric tons/year) of the global anthropogenic emissions of mercury in 2005 (UNEP, 2008).

To address this significant source category of emissions, UNEP's partnership area "Reduction of Mercury Releases from Coal Combustion" was formed. The partnership is currently implementing the project on "Reducing Mercury Emissions from Coal Combustion in the Energy Sector." The project has produced UNEP's Process Optimization Guidance (POG) summarizing practices capable of providing reduction of mercury emissions from coal-fired power plants (UNEP, 2011). The POG was used to help determine the approaches for mercury emission reduction at two coal-fired power plants in Russia.

\section{Materials and Methods}

To control particulate matter (PM) emissions from coalfired power plants in Russia, about $60 \%$ of the plants have electrostatic precipitators (ESPs) installed, and about $30 \%$ have wet PM scrubbers installed. Thus, the two UNEP Coal Partnership projects address the majority of PM emission control configurations occurring in Russia.

The first project modified the wet PM scrubber installed on boiler \#12 of Toliatti thermal plant to allow for addition of chemical reagents (oxidants) into the closed-loop liquid spray system. Typical mercury removal in unmodified wet PM scrubbers is 20 to $25 \%$. The addition of oxidants into the wet PM scrubber system would be expected to increase mercury removal by the scrubber. The amount of removal depends on the liquidto-gas ratio and mercury speciation in the flue gas. In the first step, laboratory screening of potential oxidants took place and, as a result, sodium hypochlorite $(\mathrm{NaClO})$ was selected for pilot demonstration. Figure 1 below presents the summary of results. The addition of $0.7 \mathrm{~kg}$ of $19 \%$ $\mathrm{NaClO} /$ ton of water/hour while maintaining liquid-to gas ratio at 0.1 liter $/ \mathrm{Nm}^{3}$ resulted in significant improvement of mercury capture from $20 \%$ total mercury removal without the additive up to $60 \%$ removal with the additive. The objective of the second demonstration was to investigate the effectiveness of duct sorbent injection in conjunction with an ESP. The project was conducted at the 8 -MW $\left(40,000 \mathrm{~m}^{3} / \mathrm{h}\right)$ pilot plant ESP facility located at the $300-\mathrm{MW}$ Cherepetskaya power plant outside of 


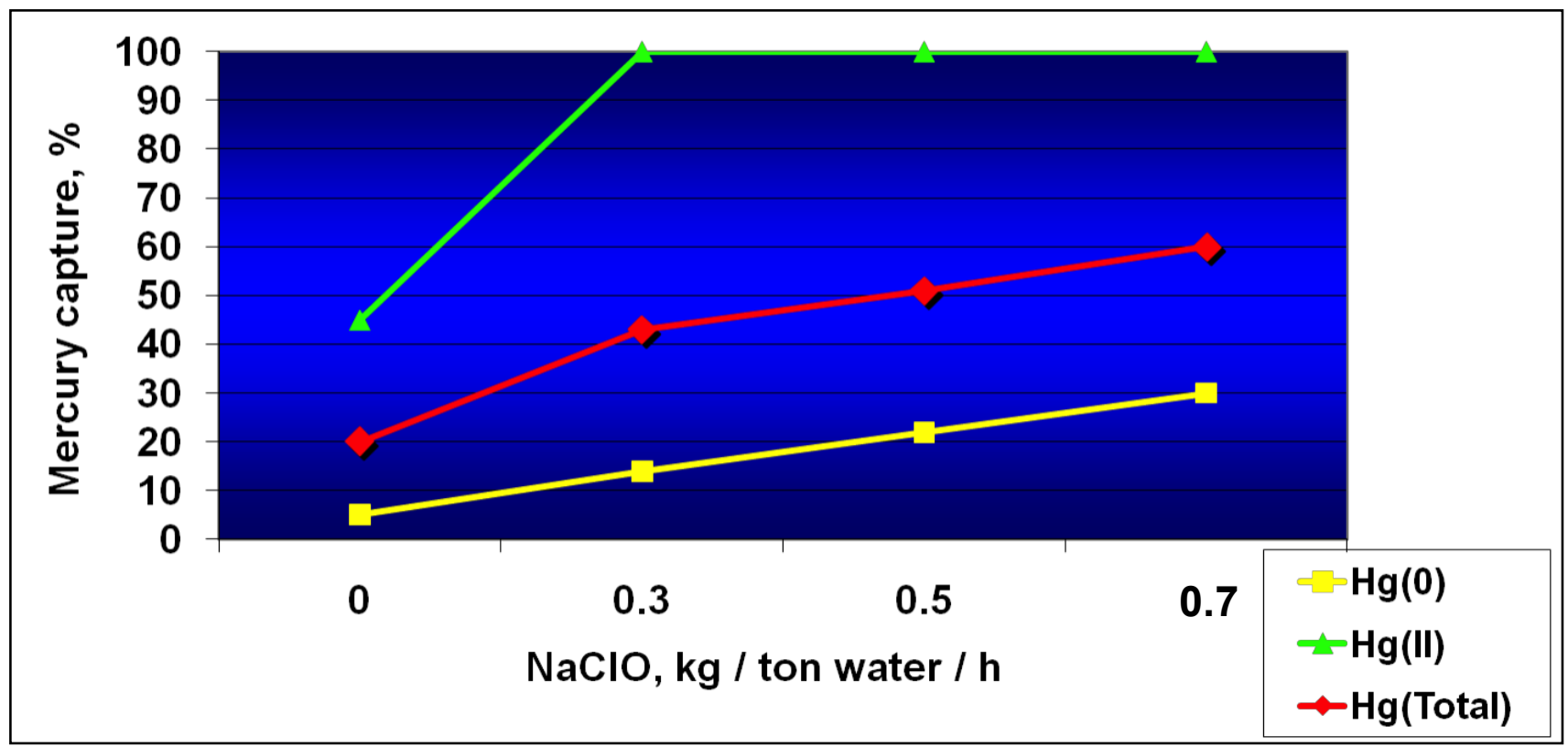

Figure 1: The effect of oxidant on mercury capture by wet PM scrubber.

Moscow. The plant currently fires Kuznetsky coal that is used widely in Russia. The injection of activated carbon, both standard and halogenated into the flue gas was tested. Preliminary results indicate about $90 \%$ mercury removal. The project has utilized carbon traps (US EPA Mercury Toolkit) for sampling and mercury content determination in flue gas.

\section{Conclusions}

UNEP's POG has been successfully used to select mercury emission reduction scenarios for two demonstrations at coal-fired power plants in Russia. Up to about $60 \%$ of mercury removal was accomplished by addition of modest amounts of oxidant to a wet PM scrubber. Sorbent injection upstream of an ESP resulted in about $90 \%$ mercury removal.

\section{Acknowledgements}

The authors acknowledge financial supports from the European Commission, Environment Canada, Sweden, and USA. Donation of activated carbons by Albemarle for demonstration in Russia is also acknowledged.

\section{References}

UNEP (2011). Process Optimization Guidance for Reducing Mercury Emissions from Coal Combustion in Power Plants, January 2011.

UNEP (2008). The Global Atmospheric Mercury Assessment: Sources, Emissions and Transport, United Nations Environmental Programme, Chemicals Branch, DTIE, Geneva, Switzerland, December 2008. 